\title{
m-Interpenetrated 3D Covalent Organic Frameworks from Distorted Polycyclic Aromatic Hydrocarbons
}

\author{
Marta Martínez-Abadía, ${ }^{[\mathrm{a}]}$ Karol Strutynski, ${ }^{[\mathrm{b}]}$ Belén Lerma-Berlanga, ${ }^{[\mathrm{c}]}$ Craig T. Stoppiello, ${ }^{[\mathrm{d}, \mathrm{e}]}$ \\ Andrei N. Khlobystov, ${ }^{[\mathrm{d}, e]}$ Carlos Martí-Gastaldo, ${ }^{[c]}$ Akinori Saeki, ${ }^{[f]}$ Manuel Melle-Franco, ${ }^{*[b]}$ and \\ Aurelio Mateo-Alonso*[a,g]
}

[a] Prof. Dr. A. Mateo-Alonso and Dr. M. Martínez-Abadía

POLYMAT, University of the Basque Country UPV/EHU, Avenida de Tolosa 72, E-20018 Donostia-San Sebastian, Spain. E-mail: amateo@polymat.eu

[b] Prof. Dr. M. Melle-Franco and Dr. K. Strutynski

CICECO - Aveiro Institute of Materials, Department of Chemistry, University of Aveiro, 3810-193 Aveiro, Portugal.

E-mail: manuelmelle.research@gmail.com

[c] Prof. Dr. C. Martí-Gastaldo

Instituto de Ciencia Molecular, Universidad de Valencia, 46980 Paterna, Spain.

[d] Prof. Dr. Khlobystov and Dr. C. Stoppiello

School of Chemistry, University of Nottingham, University Park, Nottingham NG7 2RD, UK

[e] Prof. Dr. Khlobystov and Dr. C. Stoppiello

The Nanoscale and Microscale Research Centre, University of Nottingham, University Park, Nottingham NG7 2RD, UK.

[f] Prof. Dr. A. Saeki

Department of Applied Chemistry, Graduate School of Engineering, Osaka University, Suita, Osaka 565-0871, Japan.

[g] Prof. Dr. A. Mateo-Alonso

Ikerbasque, Basque Foundation for Science, Bilbao, Spain

Supporting information for this article is given via a link at the end of the document.

\begin{abstract}
Three-dimensional covalent organic frameworks (3D COFs) with a pcu topology have been obtained from distorted polycyclic aromatic hydrocarbons acting as triangular antiprismatic $\left(D_{3 d}\right)$ nodes. Such 3D COFs are six-fold interpenetrated as the result of interframework $\pi$-stacking, which enable charge transport properties that are not expected for 3D COFs.
\end{abstract}

Reticular chemistry provides a powerful approach to blueprint and synthesize crystalline solids that relies on the concepts of modularity and predictability. ${ }^{[1]}$ The combination of these two concepts with dynamic covalent chemistry has given rise to covalent organic frameworks (COFs). These periodic networks of covalently bonded organic monomers have attracted a lot of attention from different perspectives, including synthetic, structural, supramolecular and electronic. ${ }^{[2]}$

The structure and properties of COFs are directly related to the symmetry and connectivity of the monomers used. Therefore, the rational design of monomers has become a fundamental tool in the design of COFs with specific structures and properties. The (co)polymerization of coplanar 2D polygonal monomers produce crystalline $\pi$-stacks of 2D COF layers, along which charge-carriers can move. ${ }^{[3]}$ Meanwhile, the (co)polymerization of either non-coplanar 2D polygonal monomers or of $3 \mathrm{D}$ polyhedral monomers produce $3 \mathrm{D}$ COFs, ${ }^{\text {[2a }}$ $2 \mathrm{~d}, 2 \mathrm{~h}, 2 \mathrm{n}, 2 \mathrm{o}$ in which the lack of $\pi$-stacking makes difficult chargetransport, but enables light-emitting properties. ${ }^{[4]}$

Even if 3D COFs show distinctive properties, they remain largely unexplored with $2 \mathrm{D}$ frameworks being the dominant motif. ${ }^{[2 a-d, 2 f-h, ~ 2 j, ~ 2 k, ~ 2 m, ~ 20] ~ T h i s ~ i s ~ i n ~ p a r t ~ b e c a u s e ~ o f ~ t h e ~ l o w ~ n u m b e r ~}$ of $3 \mathrm{D}$ organic monomers available, their limited geometries (imposed by the $\mathrm{sp}, \mathrm{sp}^{2}$ and $\mathrm{sp}^{3}$ hybridization of carbon), and reduced points of extension. For instance, most of the reported $3 \mathrm{D}$ COFs have been obtained from tetrahedral $\left(T_{\mathrm{d}}\right)^{[4-5]}$ monomers and only a few exceptions of 3D COFs have been obtained from triangular $\left(D_{3}\right),{ }^{[6]}$ square $\left(D_{4}\right),{ }^{\left[{ }^{[6]}\right.}$ triangular prismatic
$\left(D_{3 h}\right)^{[7]}$ and cubic $\left(O_{h}\right)^{[8]}$ monomers. This is illustrated by the small number of topologies reported for 3D COFs (acs, ${ }^{[\mathrm{b}]} \mathrm{bcu},{ }^{[8]}$ bor, ${ }^{[5 e]} \mathrm{ctn},{ }^{[5 \mathrm{e}]} \mathrm{dia},{ }^{[5 a-d]} \mathrm{ffc},{ }^{[9]} \mathrm{fjh},{ }^{[6 \mathrm{cc}]} \mathrm{lon},{ }^{[5 \mathrm{a}]} \mathrm{pts},{ }^{[4,}{ }^{5 f-i]} \mathrm{rra},{ }^{[5 j]} \mathrm{srs},{ }^{[6 a]}$ $\left.s t p^{[7 a]}, t b o^{[6 b]}\right)$, compared to the large number of topologies reported for metal-organic frameworks $(>60) .^{[10]}$

Another aspect that has been identified to influence the formation, characterization and properties of $3 \mathrm{D}$ COFs is

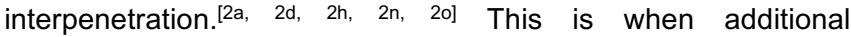
framework(s) intergrow in the empty space generated by the framework itself. Although interpenetration is often regarded as something to be avoided because of its detrimental effect on porosity, ${ }^{[2 d, 21,2 n, 20]}$ its potential benefits on the overall properties of 3D COFs remains practically unexplored. ${ }^{[11]}$

Herein, we report the synthesis of $3 \mathrm{D}$ COFs from a distorted polycyclic aromatic hydrocarbon monomer with a triangular antiprismatic $\left(D_{3 \mathrm{~d}}\right) \quad$ structure, namely 2,3,6,7,10,11,14,15,18,19,22,23-dodecahydroxy-cata-

hexabenzocoronene (3D-HBC, Figure 1A). The structure of 3D$\mathrm{HBC}$ deviates from the typical graphitic geometries because of the steric congestion between hydrogens on the peripheral rings, which forces, alternately, the catechol residues on the outer rim above and below the coronene plane. The copolymerization of 3D-HBC with linear diboronic acids gives rise to 3D COFs with a previously unreported pcu net (Marta-COF-3 and 4, Figure 1A). This topology shows a trigonal trapezohedral lattice and a tight six-fold interpenetration that lines up the face-on triangular micropores into open channels (Figures 1B-E and S1). The interpenetrated structure is held together by interframework $\pi$ stacking (to which we refer to as $\pi$-interpenetration or inter- $\pi-$ netration) between the 3D-HBC nodes, which is favored by the inherent rigidity, structural self-complementarity and tendency to self-assemble of cata-hexabenzocoronenes. Such inter-тnetration enables charge transport properties that are not expected in conventional 3D COFs and that are similar to those intrinsic of 2D COFs. 
3D-HBC was synthesized by ether cleavage of 2,3,6,7,10,11,14,15,18,19,22,23-dodecamethoxy-cata-

hexabenzocoronene ${ }^{[12]}$ in the presence of $\mathrm{BBr}_{3}$ in a quantitative yield. Marta-COF-3 and 4 were synthesized by solvothermal condensation of 3D-HBC with benzene-1,4-diboronic acid and with pyrene-2,7-diboronic acid, respectively (Figure 1), in $N, N$ dimethylacetamide/mesitylene $(1: 1, \mathrm{v} / \mathrm{v})$ at $140{ }^{\circ} \mathrm{C}$ for 7 days in sealed pre-scored ampoules, which afforded green crystalline powders in $\sim 90 \%$ yields.

The FT-IR spectra of the powders of Marta-COF-3 and 4 confirmed the successful condensation of the precursors with the appearance of strong $\mathrm{C}-\mathrm{O}$ stretching band distinctive for boronate ester five-membered rings at 1346 and $1347 \mathrm{~cm}^{-1}$, respectively, together with strongly attenuated signals of the hydroxyls of the boronic acid (Figures S2 and S3). The UV-vis absorption spectra of the powders show similar absorption patterns in the vis region consistent with the absorption of the 3D-HBC nodes (Figure S4). The solid-state ${ }^{13} \mathrm{C}$ crosspolarization magic angle spinning (CP/MAS) NMR signals of both 3D COFs (Figures S5 and S6) are consistent with the aromatic nature of the monomers, meanwhile the CP/MAS ${ }^{11} \mathrm{~B}$ NMR spectra (Figures S7 and S8) show single peaks attributed to a single type of boronate ester linkage. Marta-COF-3 and 4 show a solvent stability similar to that of other boronate ester COFs and hydrolyze in the presence of protic solvents. Thermal gravimetric analysis reveals that Marta-COF- 3 and 4 were stable up to 257 and $311^{\circ} \mathrm{C}$ under $\mathrm{N}_{2}$ (Figure S9).

A)

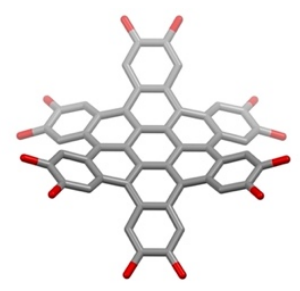

Front View

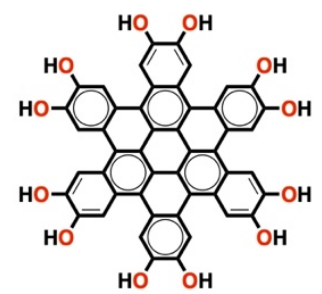

3D-HBC

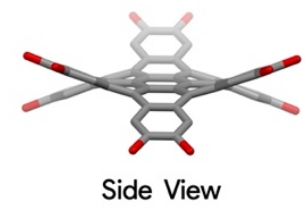

Side View
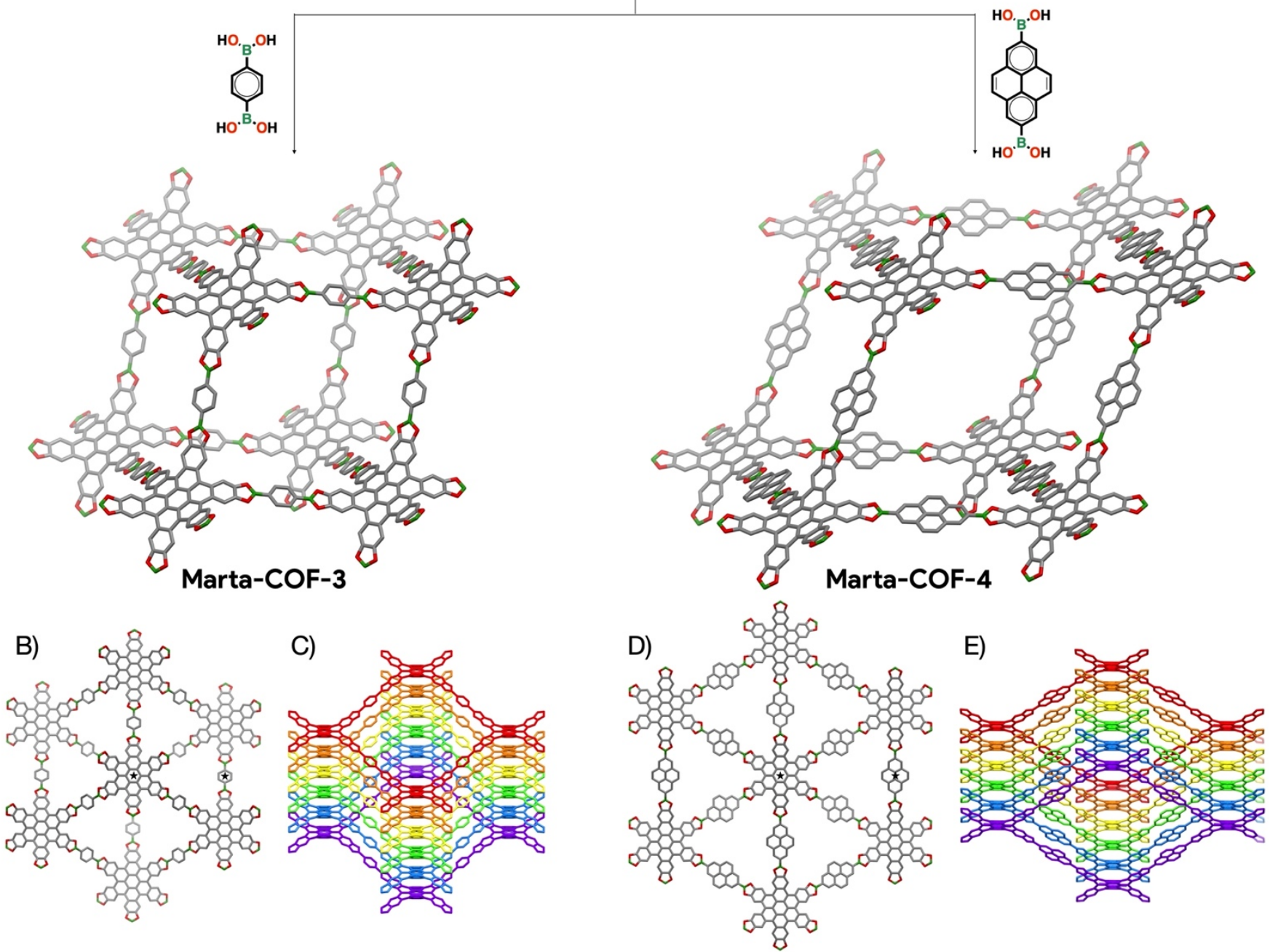

Figure 1. A) Structure of 3D-HBC. Synthesis and reconstructed crystal structures of a single framework of Marta-COF-3 and 4. B,D) Face-on and C,E) edge-on views of the reconstructed crystal structures of the complete 6-fold interpenetrated structures of Marta-COF-3 and 4 showing the triangular pores and the interframework $\pi$-stacking (inter-m-netration). Stars indicate the distances discussed in the TEM section. 
Crystallinity was first confirmed by powder X-ray diffraction (PXRD) measurements, which showed several intense diffraction peaks with a similar pattern for Marta-COF-3 and 4 but at different $2 \theta$ values (Figures $2 \mathrm{~A}$ and $2 \mathrm{E}$ ). This implies a similar structure for both 3D COFs but with different dimensions, which is consistent with the different length of the linkers. Pawley refinement yielded trigonal unit cells with excellent agreement factors $\left(a=b=20.22 \AA, c=7.91 \AA, R_{\mathrm{wp}}=5.70 \%\right.$, and $R_{\mathrm{p}}=4.83 \%$ for Marta-COF-3 $a=b=24.60 \AA, c=7.95 \AA$, $R_{\mathrm{wp}}=8.50 \%$, and $R_{\mathrm{p}}=2.97 \%$ for Marta-COF-4) (Figures $\mathrm{S} 10$ and S11). The atomic structure of Marta-COF-3 and 4 was elucidated by comparing the simulated PXRD patterns of computed different crystal structures with the experimental ones. Crystal structures were computed by unconstrained minimizations initially performed with Tight-Binding (TB) and refined with DFT (PBE-MBD/light) with $\mathrm{DFTB}+{ }^{[13]}$ and FHIaims ${ }^{[14]}$ respectively (details in supporting information). Given the rigidity, symmetry and valency of 6 of 3D-HBC, a $D_{3 \mathrm{~d}}$ trigonal trapezohedral lattice with a $(2,6)$-connected $p c u$ topology was constructed for Marta-COF-3 and 4 (Figure 1A). This lattice was distorted by introducing different twist angles at the 3D-HBC nodes (Figure S12), which implicitly give rise to different degrees of interpenetration (three-, six- and nine-fold). The simulated PXRD diffractograms of the six-fold interpenetrated structure were in excellent agreement with the experimental ones (Figures 1B-E, 2A, 2E, S13 and S14) and also with the values obtained from the Pawley refinement. Concurrently, these six-fold interpenetrated structures were also found to show the most favorable potential energies. Interpenetration is strongly favored in these COFs by means of interframework m-stacking between the 3D-HBC nodes, which is consistent with the structural selfcomplementarity and the tendency to self-assemble of catahexabenzocoronenes. ${ }^{[3 \mathrm{j},}{ }^{15]}$ To verify the preferential $A A$ arrangement of the nodes, the reconstructed crystal structures of the $3 D$ COFs with $A B$ node arrangements were computed with TB for $3 \times 3 \times 3$ supercells, yielding quasi-AA node arrangements upon minimization with negligible energy differences (Figure S15). All simulations were run on $P 1$ cells without symmetry constrains. Upon symmetrization, Marta-COF3 and 4 computed structures were found to belong to the $P 31 \mathrm{~m}$ space group. For Marta-COF-3 (Figure 2A) the diffraction peaks at $5.31^{\circ}, 8.95^{\circ}, 13.45^{\circ}$, and $15.32^{\circ}$ can be assigned to the $(100)$, (1-20), (210), and (3-30) Bragg peaks, respectively. For MartaCOF-4 (Figure 2B) the peaks at $4.31^{\circ}, 7.36^{\circ}, 8.46^{\circ}, 11.19^{\circ}$, $12.74^{\circ}$, and $16.73^{\circ}$ can be assigned to the (010), (1-20), (020), (210), (3-30) and (4-40) Bragg peaks, respectively.

The tight six-fold interpenetrated $p c u$ topology of MartaCOF-3 and 4 gives rise to uniform triangular micropore channels (Figures 1B-E) in spite of the different porosities of the single nets. Nitrogen adsorption measurements at $77 \mathrm{~K}$ show in both cases a type I sorption isotherm (Figures $2 \mathrm{~B}$ and $2 \mathrm{~F}$ ) with a mesoporous tail at high relative pressures, suggesting intergrain mesoporosity associated to small particle size. The BrunauerEmmet-Teller (BET) surface areas are 778 and $723 \mathrm{~m}^{2} \mathrm{~g}^{-1}$, respectively for Marta-COF-3 and 4 , which are close to the Zeo++ theoretical values of 625 and $1075 \mathrm{~m}^{2} \mathrm{~g}^{-1}$. The higher BET surface area of Marta-COF-3 can be ascribed to the higher crystallinity, in agreement with microscopy characterization (see below). The positive deviation of the BET surface area from the theoretical value in the case of Marta-COF-3 can be ascribed to the known overestimation of surface areas by the BET method in materials with micropores between 0.6 and $1.3 \mathrm{~nm} \cdot{ }^{[16]}$ The pore size distributions calculated with Density Functional Theory (DFT) (Figures 2C and 2G) give a dominant pore centered at $0.63 \mathrm{~nm}$ in both COFs, consistent with the theoretical pore sizes of 0.60 and $0.64 \mathrm{~nm}$, respectively for Marta-COF-3 and 4 .
A)

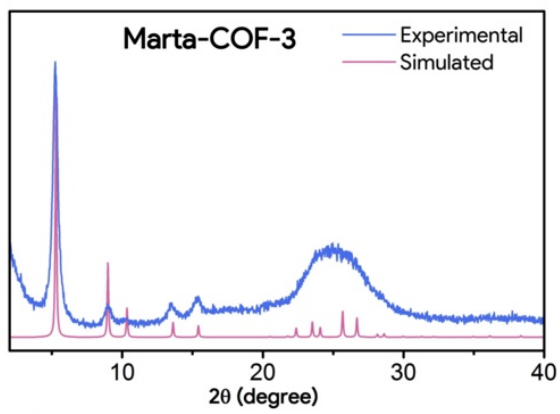

E)

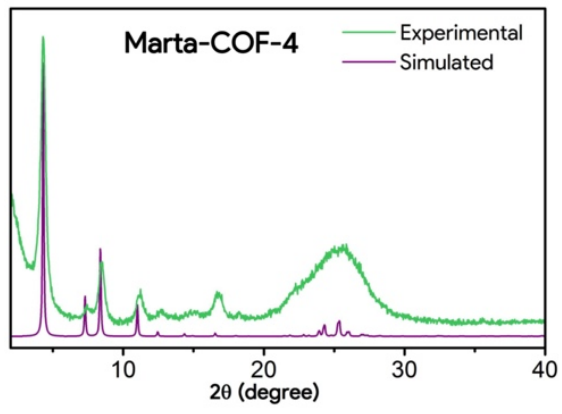

B)

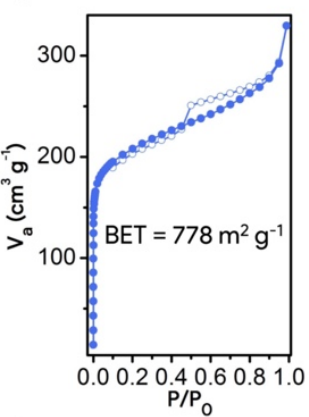

F)

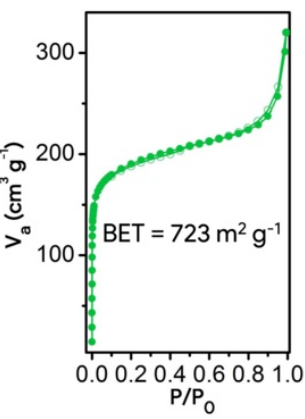

C)

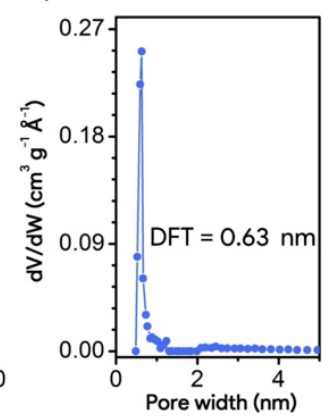

G)

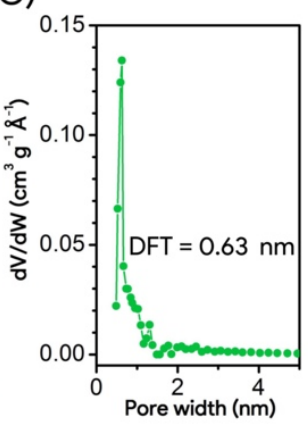

D)

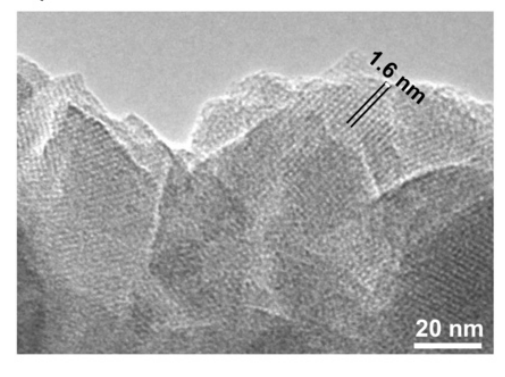

$\mathrm{H})$

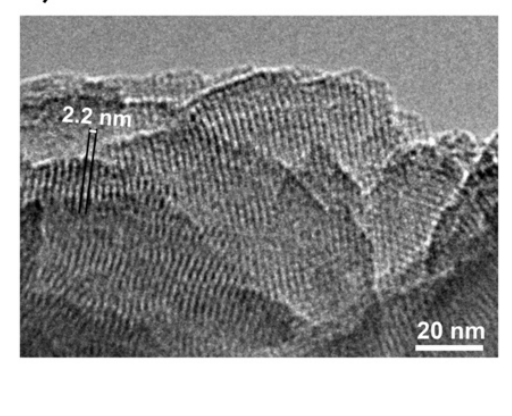

Figure 2. Experimental and simulated PXRD patterns for the reconstructed crystal structures of A) Marta-COF-3 and E) Marta-COF-4. Nitrogen adsorption and desorption isotherms at $77 \mathrm{~K}$ and DFT pore size distribution, respectively, of B,C) Marta-COF-3 and F,G) Marta-COF-4. HR-TEM images of D) Marta-COF-3 and H) Marta-COF-4 
The crystallinity and porous structure of Marta-COF-3 and 4 was also evidenced by scanning electron microscopy (SEM) and high-resolution transmission electron microscopy (HR-TEM). SEM revealed that crystallites of COF have approximately triangular shapes, with lateral dimensions of 100-200 nm and the thickness of $\sim 20 \mathrm{~nm}$ (Figure S16), which implies a preferential growth of COF layers in the $a-b$ crystallographic plane during the synthesis. The nanocrystallites are arranged in a pattern of a desert-rose crystal, where the 'petals' (e.g. triangular crystallites of COF flattened along the $c$ crystallographic axis) are fanning open from the center of the crystal cluster (Figure S16). Removal of the top layer of the COF rosette-like particles demonstrated mesoporous internal voids of 20-50 nm (Figure S17), similar to the mesoporous particles of conjugated microporous polymers. ${ }^{[17]}$ Crystallites with periodic channel-like features were observed by HR-TEM in both MartaCOF-3 and 4 samples but with differences in the channel widths (1.6 and $2.2 \mathrm{~nm}$, respectively) (Figure 2D, 2H, S18 and S19). These different distances are in excellent agreement with the centroid-to-centroid distances between 3D-HBC and the opposite benzene or pyrene linker (indicated with stars in Figure $1 \mathrm{~B}$ and 1D) on the reconstructed crystal structures (1.6 and 2.3 $\mathrm{nm}$, respectively for Marta-COF-3 and 4).

Given the extensive interframework m-stacking of MartaCOF-3 and 4, their charge transport properties were evaluated by flash-photolysis time-resolved microwave conductivity (FPTRMC). ${ }^{[18]}$ FP-TRMC allows estimating the pseudophotoconductivity or intrinsic mobility $(\varphi \Sigma \mu$, where $\varphi$ : the charge carrier generation yield, $\Sigma \mu$ : the sum of charge carrier mobilities) directly on powder samples. The samples of Marta-COF-3 and 4 showed $\varphi \Sigma \mu$ maximum values $\left(\varphi \Sigma \mu_{\max }\right)$ of $1.2 \times 10^{-4}$ and $1.3 \times$ $10^{-4} \mathrm{~cm}^{2} \mathrm{~V}^{-1} \mathrm{~s}^{-1}$, respectively (Figure 3). These $\varphi \Sigma \mu_{\max }$ values are of the same order of magnitude as those generally observed in $\pi$-stacked 2D COFs ${ }^{[3]}$ (with $\varphi \Sigma \mu_{\max }$ values that fall between $10^{-5}$ and $10^{-4} \mathrm{~cm}^{2} \mathrm{~V}^{-1} \mathrm{~s}^{-1}$, Table S1) and even double those observed in 2D COFs constituted of the same components (0.6 $\left.\times 10^{-4} \mathrm{~cm}^{2} \mathrm{~V}^{-1} \mathrm{~s}^{-1}\right){ }^{[3]]}$ The nearly identical $\varphi \sum \mu_{\max }$ values of Marta-COF-3 and 4 indicate that charge transport takes place preferentially across the 3D-HBC stacks.

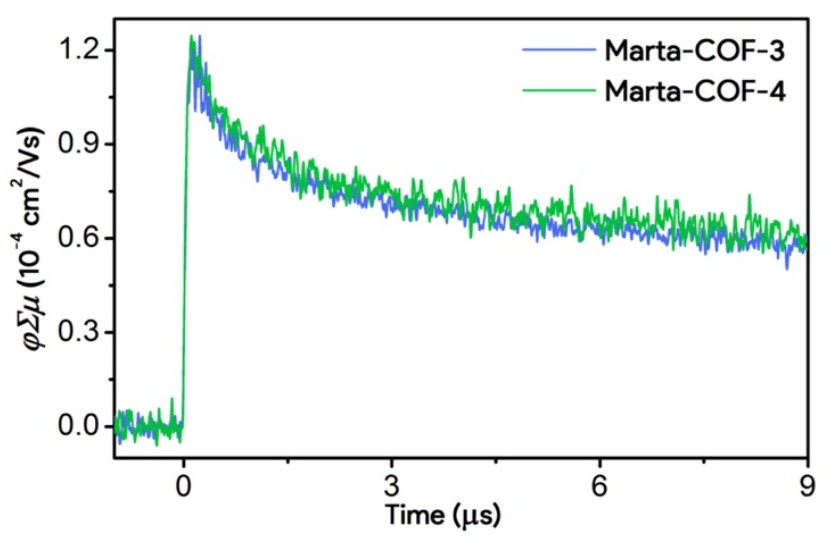

Figure 3. $\varphi \Sigma \mu$ transients of Marta-COF-3 and 4 measured by FP-TRMC.
To conclude, we have described an approach to prepare 3D COFs (Marta-COF-3 and 4) with a trigonal trapezohedral lattice and a previously unreported $p c u$ topology from a distorted polycyclic aromatic hydrocarbon with a triangular antiprismatic structure (3D-HBC). The excellent agreement between structural characterization and calculations confirm that Marta-COF-3 and 4 show a tight 6 -fold interpenetrated structure held together by interframework $\pi$-stacking across the 3D-HBC nodes. Such inter- $\pi$-netration enables charge transport properties that are not expected for 3D COFs and that are similar to those observed in $\pi$-stacked 2D COFs. Thereby, providing new application perspectives both for framework interpenetration and for 3D COFs. Overall, this work illustrates that distorted aromatics offer new possibilities to design organic monomers with structures that deviate from standard graphitic geometries, and thus, to design COFs with unprecedented architectures and properties.

\section{Acknowledgements}

This work was carried out with support from the Basque Science Foundation for Science (Ikerbasque), POLYMAT, the University of the Basque Country (Grupo de Investigación GIU17/054), Gobierno de España (Ministerio de Ciencia e Innovación, Plan Estatal de Investigación Científica y Técnica y de Innovación), Gobierno Vasco (PIBA and BERC programmes) and acknowledge technical and human support provided by SGlker of UPV/EHU and European funding (ERDF and ESF). This project has received funding from the European Research Council (ERC) under the European Union's Horizon 2020 research and innovation programme (Grant Agreement No. 722951). This project has received funding from the European Union's Horizon 2020 research and innovation programme under grant agreement No 664878 and No 899895. In addition, support through the project IF/00894/2015 and within the scope of the project CICECO-Aveiro Institute of Materials, UIDB/50011/2020 \& UIDP/50011/2020, financed by national funds through the Portuguese Foundation for Science and Technology/MCTES is gratefully acknowledged.

Keywords: polycyclic aromatic hydrocarbons $\cdot$ non-planar aromatics $\cdot 3 \mathrm{D}$ covalent organic frameworks $\cdot$ interpenetration $•$ charge transport

[1] O. M. Yaghi, M. J. Kalmutzki, C. S. Diercks, Introduction to Reticular Chemistry: Metal-Organic Frameworks and Covalent Organic Frameworks, Wiley, 2019.

[2] (a) C. S. Diercks, O. M. Yaghi, Science 2017, 355, eaal1585; (b) R. P. Bisbey, W. R. Dichtel, ACS Cent. Sci. 2017, 3, 533-543; (c) Y. Jin, Y. Hu, W. Zhang, Nat. Rev. Chem. 2017, 1, 0056; (d) X. Ma, T. F. Scott, Commun. Chem. 2018, 1, 98; (e) M. S. Lohse, T. Bein, Adv. Funct. Mater. 2018, 28, 1705553; (f) S. Kandambeth, K. Dey, R. Banerjee, J. Am. Chem. Soc. 2019, 141, 1807-1822; (g) H. Wang, Z. Zeng, P. Xu, L. Li, G. Zeng, R. Xiao, Z. Tang, D. Huang, L. Tang, C. Lai, D. Jiang, Y. Liu, H. Yi, L. Qin, S. Ye, X. Ren, W. Tang, Chem. Soc. Rev. 2019, 48, 488-516; (h) S. J. Lyle, P. J. Waller, O. M. Yaghi, Trends in Chemistry 2019, 1, 172-184; (i) Y. Li, W. Chen, G. Xing, D. Jiang, L. Chen, Chem. Soc. Rev. 2020, 49, 2852-2868; (j) S. B. Alahakoon, S. D. Diwakara, C. M. Thompson, R. A. Smaldone, Chem. Soc. Rev. 2020, 49, 1344-1356; (k) K. Geng, T. He, R. Liu, K. T. Tan, Z. Li, S. Tao, Y. Gong, Q. Jiang, D. Jiang, Chem. Rev. 2020, 10.1021/acs.chemrev.9b00550; (I) K. Geng, V. Arumugam, H. Xu, Y. Gao, D. Jiang, Prog. Polym. Sci. 2020, 108, 101288; (m) M. MartínezAbadía, A. Mateo-Alonso, Adv. Mater. 2020, 32, 2002366; (n) B. Gui, G. Lin, H. Ding, C. Gao, A. Mal, C. Wang, Acc. Chem. Res. 2020, 53, 22252234; (o) X. Guan, F. Chen, Q. Fang, S. Qiu, Chem. Soc. Rev. 2020, 49, 1357-1384. 
[3] (a) S. Dalapati, M. Addicoat, S. Jin, T. Sakurai, J. Gao, H. Xu, S. Irle, S. Seki, D. Jiang, Nat. Commun. 2015, 6, 7786; (b) H. Ding, Y. Li, H. Hu, Y. Sun, J. Wang, C. Wang, C. Wang, G. Zhang, B. Wang, W. Xu, D. Zhang, Chem. Eur. J. 2014, 20, 14614-14618; (c) S. Jin, T. Sakurai, T. Kowalczyk S. Dalapati, F. Xu, H. Wei, X. Chen, J. Gao, S. Seki, S. Irle, D. Jiang, Chem. Eur. J. 2014, 20, 14608-14613; (d) X. Feng, L. Chen, Y. Honsho, O. Saengsawang, L. Liu, L. Wang, A. Saeki, S. Irle, S. Seki, Y. Dong, D. Jiang, Adv. Mater. 2012, 24, 3026-3031; (e) X. Feng, L. Liu, Y. Honsho, A Saeki, S. Seki, S. Irle, Y. Dong, A. Nagai, D. Jiang, Angew. Chem. Int. Ed. 2012, 51, 2618-2622; (f) X. Ding, X. Feng, A. Saeki, S. Seki, A. Nagai, D. Jiang, Chem. Commun. 2012, 48, 8952-8954; (g) S. Wan, F. Gándara, A Asano, H. Furukawa, A. Saeki, S. K. Dey, L. Liao, M. W. Ambrogio, Y. Y Botros, X. Duan, S. Seki, J. F. Stoddart, O. M. Yaghi, Chem. Mater. 2011 23, 4094-4097; (h) X. Ding, J. Guo, X. Feng, Y. Honsho, J. Guo, S. Seki, P. Maitarad, A. Saeki, S. Nagase, D. Jiang, Angew. Chem. Int. Ed. 2011 50, 1289-1293; (i) X. Ding, L. Chen, Y. Honsho, X. Feng, O Saengsawang, J. Guo, A. Saeki, S. Seki, S. Irle, S. Nagase, V. Parasuk, D. Jiang, J. Am. Chem. Soc. 2011, 133, 14510-14513; (j) M. Martínez Abadía, C. T. Stoppiello, K. Strutynski, B. Lerma-Berlanga, C. MartíGastaldo, A. Saeki, M. Melle-Franco, A. N. Khlobystov, A. Mateo-Alonso, J. Am. Chem. Soc. 2019, 141, 14403-14410; (k) S. Thomas, H. Li, R. R Dasari, A. M. Evans, I. Castano, T. G. Allen, O. G. Reid, G. Rumbles, W. R. Dichtel, N. C. Gianneschi, S. R. Marder, V. Coropceanu, J.-L. Brédas, Mater. Horiz. 2019, 6, 1868-1876.

[4] (a) G. Lin, H. Ding, D. Yuan, B. Wang, C. Wang, J. Am. Chem. Soc. 2016 138, 3302-3305; (b) H. Ding, J. Li, G. Xie, G. Lin, R. Chen, Z. Peng, C Yang, B. Wang, J. Sun, C. Wang, Nat. Commun. 2018, 9, 5234

[5] (a) T. Ma, E. A. Kapustin, S. X. Yin, L. Liang, Z. Zhou, J. Niu, L.-H. Li, Y. Wang, J. Su, J. Li, X. Wang, W. D. Wang, W. Wang, J. Sun, O. M. Yaghi, Science 2018, 361, 48-52; (b) Y.-X. Ma, Z.-J. Li, L. Wei, S.-Y. Ding, Y.-B Zhang, W. Wang, J. Am. Chem. Soc. 2017, 139, 4995-4998; (c) C. Wang Y. Wang, R. Ge, X. Song, X. Xing, Q. Jiang, H. Lu, C. Hao, X. Guo, Y. Gao, D. Jiang, Chem. Eur. J. 2018, 24, 585-589; (d) D. Beaudoin, T. Maris, J. D. Wuest, Nat Chem. 2013, 5, 830-834; (e) H. M. El-Kaderi, J. R. Hunt, J. L. Mendoza-Cortés, A. P. Côté, R. E. Taylor, M. O'Keeffe, O. M. Yaghi, Science 2007, 316, 268-272; (f) C. Gao, J. Li, S. Yin, G. Lin, T. Ma, Y. Meng, J. Sun, C. Wang, Angew. Chem. Int. Ed. 2019, 58, 9770-9775; (g) L. Liang, Y Qu, W. D. Wang, J. Han, Y Luo, W Yu, G.-L. Yin, Z-P Wang, L. Zhang, J. Ni, J. Niu, J. Sun, T. Ma, W. Wang, Angew. Chem. Int Ed. 2020, 59, 17991-17995; (h) G. Lin, H. Ding, R. Chen, Z. Peng, B Wang, C. Wang, J. Am. Chem. Soc. 2017, 139, 8705-8709; (i) C. Gao, J. Li, S. Yin, J. Sun, C. Wang, J. Am. Chem. Soc. 2020, 142, 3718-3723; (j) Y. Zhang, J. Duan, D. Ma, P. Li, S. Li, H. Li, J. Zhou, X. Ma, X. Feng, B. Wang, Angew. Chem. Int. Ed. 2017, 56, 16313-16317.

[6] (a) O. Yahiaoui, A. N. Fitch, F. Hoffmann, M. Fröba, A. Thomas, J. Roeser, J. Am. Chem. Soc. 2018, 140, 5330-5333; (b) X. Kang, X. Han, C. Yuan, C. Cheng, Y. Liu, Y. Cui, J. Am. Chem. Soc. 2020, 142, 16346-16356; (c) H. L. Nguyen, C. Gropp, Y. Ma, C. Zhu, O. M. Yaghi, J. Am. Chem. Soc. 2020 142, 20335-20339.

[7] (a) H. Li, J. Ding, X. Guan, F. Chen, C. Li, L. Zhu, M. Xue, D. Yuan, V. Valtchev, Y. Yan, S. Qiu, Q. Fang, J. Am. Chem. Soc. 2020, 142, 1333413338; (b) Q. Zhu, X. Wang, R. Clowes, P. Cui, L. Chen, M. A. Little, A. I. Cooper, J. Am. Chem. Soc. 2020, 142, 16842-16848.

[8] C. Gropp, T. Ma, N. Hanikel, O. M. Yaghi, Science 2020, 370, eabd6406.

9] (a) Y. Lan, X. Han, M. Tong, H. Huang, Q. Yang, D. Liu, X. Zhao, C. Zhong, Nat. Commun. 2018, 9, 5274; (b) X. Kang, X. Wu, X. Han, C. Yuan, Y. Liu, Y. Cui, Chem. Sci. 2020, 11, 1494-1502.

[10] E. V. Alexandrov, V. A. Blatov, A. V. Kochetkov, D. M. Proserpio CrystEngComm 2011, 13, 3947-3958.

[11] T. Ma, J. Li, J Niu, L. Zhang, A S. Etman, C Lin, D Shi, P Chen, L.-H. $\mathrm{Li}, \mathrm{X}$. Du, J. Sun, W. Wang, J. Am. Chem. Soc. 2018, 140, 6763-6766.

[12] Q. Zhang, H. Peng, G. Zhang, Q. Lu, J. Chang, Y. Dong, X. Shi, J. Wei, J. Am. Chem. Soc. 2014, 136, 5057-5064.

[13] B. Hourahine, B. Aradi, V. Blum, F. Bonafé, A. Buccheri, C. Camacho, C. Cevallos, M. Y. Deshaye, T. Dumitrică, A. Dominguez, S. Ehlert, M Elstner, T. v. d. Heide, J. Hermann, S. Irle, J. J. Kranz, C. Köhler, T. Kowalczyk, T. Kubař, I. S. Lee, V. Lutsker, R. J. Maurer, S. K. Min, I. Mitchell, C. Negre, T. A. Niehaus, A. M. N. Niklasson, A. J. Page, A Pecchia, G. Penazzi, M. P. Persson, J. Řezáč, C. G. Sánchez, M. Sternberg, M. Stöhr, F. Stuckenberg, A. Tkatchenko, V. W.-z. Yu, T. Frauenheim, J. Chem. Phys. 2020, 152, 124101

[14] V. Blum, R. Gehrke, F. Hanke, P. Havu, V. Havu, X. Ren, K. Reuter, M. Scheffler, Comput. Phys. Commun. 2009, 180, 2175-2196.

[15] (a) D. Sepulveda, Y. Guan, U. Rangel, S. E. Wheeler, Org. Biomol. Chem 2017, 15, 6042-6049; (b) Y. Guan, M. L. Jones, A. E. Miller, S. E. Wheeler, Phys. Chem. Chem. Phys. 2017, 19, 18186-18193; (c) X. Shengxiong, M. Matthew, M. Qian, S. Sébastien, P. Keliang, S. M. L., N Colin, Angew. Chem. Int. Ed. 2005, 44, 7390-7394; (d) X. Guo, S. Xiao, M. Myers, Q. Miao, M. L. Steigerwald, C. Nuckolls, Proc. Natl. Acad. Sci. 2009, 106, 691-696; (e) C.-Y. Chiu, B. Kim, A. A. Gorodetsky, W. Sattler S. Wei, A. Sattler, M. Steigerwald, C. Nuckolls, Chem. Sci. 2011, 2, 14801486.

[16] M. F. de Lange, L.-C. Lin, J. Gascon, T. J. H. Vlugt, F. Kapteijn, Langmuir 2016, 32, 12664-12675.
[17] C. T. Stoppiello, H. Isla, M. Martínez-Abadía, M. W. Fay, C. D. J. Parmenter, M. J. Roe, B. Lerma-Berlanga, C. Marti-Gastaldo, A. MateoAlonso, A. N. Khlobystov, Nanoscale 2019, 11, 2848-2854.

[18] A. Saeki, Y. Koizumi, T. Aida, S. Seki, Acc. Chem. Res. 2012, 45, 11931202 
Table of Contents

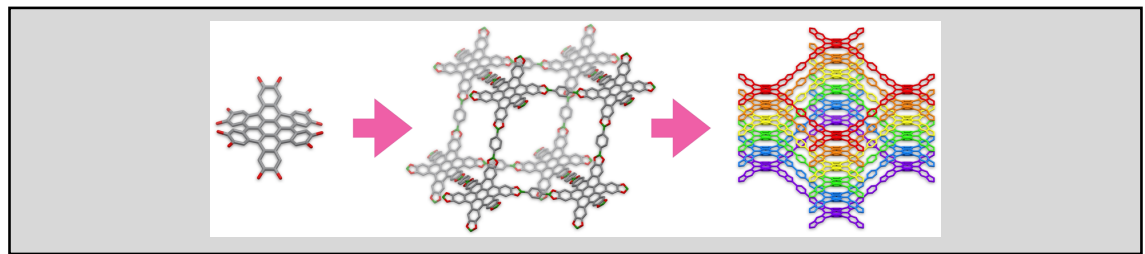

Three-dimensional covalent organic frameworks (3D COFs) have been obtained from distorted polycyclic aromatic hydrocarbon nodes. Interframework $\pi$-stacking enables charge transport properties that are not expected for 3D COFs. 